\title{
Obesity, Anthropometric Measures and Chronic Kidney Disease Complications
}

\author{
Sankar D. Navaneethan ${ }^{a, b}$ John P. Kirwan ${ }^{b, c}$ Susana Arrigain ${ }^{d}$ \\ Martin J. Schreiber ${ }^{a}$ Mark J. Sarnak ${ }^{\mathrm{e}}$ Jesse D. Schold ${ }^{\mathrm{a}} \mathrm{d}$ \\ aDepartment of Nephrology and Hypertension, Glickman Urological and Kidney Institute, \\ ${ }^{b}$ Cleveland Clinic Lerner College of Medicine of CWRU, 'Department of Pathobiology, Lerner Research Institute, \\ and d Department of Quantitative Health Sciences, Cleveland Clinic, Cleveland, Ohio, and 'Division of Nephrology, \\ Tufts Medical Center, Boston, Mass., USA
}

\section{Key Words}

Obesity $\cdot$ Body mass index $\cdot$ Waist circumference $\cdot$ Chronic kidney disease

\begin{abstract}
Background/Aims: Anthropometric measures such as body mass index (BMI) and waist circumference (WC) have differential associations with incident chronic kidney disease (CKD) and mortality. We examined the associations of BMI and WC with various CKD complications. Methods: We conducted a cross-sectional analysis of 2,853 adult participants with CKD in the National Health and Nutrition Examination Surveys 1999-2006. The associations of BMI and WC (both as categorical and continuous variables) with CKD complications such as anemia, secondary hyperparathyroidism, hyperphosphatemia, metabolic acidosis, hypoalbuminemia and hypertension were examined using logistic regression models while adjusting for relevant confounding variables. Results: When examined as a continuous variable, an increase in BMI by 2 points and in WC by $5 \mathrm{~cm}$ was associated with higher odds of secondary hyperparathyroidism, hypoalbuminemia and hypertension among those with CKD. CKD participants with $\mathrm{BMI} \geq 30$ have higher odds of hypoalbuminemia and hypertension than those with $\mathrm{BMI}<30$. CKD
\end{abstract}

participants with high WC $(>102 \mathrm{~cm}$ in men and $>88 \mathrm{~cm}$ in women) have higher odds of hypoalbuminemia and hypertension and lower odds of having anemia than those with low WC. CKD participants with BMl $<30$ and high WC (vs. BMI $<30$ and low WC) were not associated with any increase in CKD complications. Conclusions: Anthropometric measures such as BMI and WC are associated with secondary hyperparathyroidism, hypoalbuminemia and hypertension among adults with CKD. Higher WC among those with BMI $<30$ is not associated with CKD complications.

Copyright $\odot 2012$ S. Karger AG, Basel

\section{Introduction}

Chronic kidney disease (CKD) and obesity are major public health problems [1-3]. Epidemiological investigations have identified obesity as an independent risk factor for the development of CKD and the progression of CKD to ESRD in the general population [4]. Potential mechanisms that might mediate these associations include insulin resistance, increased inflammation, higher oxidative stress and endothelial dysfunction seen among those who are obese [5]. While body mass index (BMI), an anthropometric measure of whole body adiposity has been

\section{KARGER}

Fax +4161306 1234

E-Mail karger@karger.ch

www.karger.com (c) 2012 S. Karger AG, Basel

0250-8095/12/0363-0219\$38.00/0

Accessible online at:

www.karger.com/ajn
Sankar D. Navaneethan, MD, MPH

Department of Nephrology and Hypertension

Glickman Urological and Kidney Institute, Cleveland Clinic

9500 Euclid Avenue-Q7, Cleveland, OH 44195 (USA)

Tel. +1 216636 9230, E-Mail navanes@ccf.org 
associated with the development of $\mathrm{CKD}$, previous studies that examined the association of BMI and mortality showed paradoxical results in dialysis and renal transplant recipients $[6,7]$. Even though widely used, a major limitation of the BMI measure is its inability to differentiate fat mass and muscle mass which may have opposite associations with mortality $[8,9]$.

Waist circumference (WC), a measure of visceral or abdominal adiposity is associated with subclinical inflammation independent of BMI [10]. In the general population, while some studies report that measures of abdominal adiposity are better predictors of cardiovascular disease and mortality, others claim that central adiposity measures such as WC and waist-to-hip ratio (WHR) do not provide more prognostic information than $\mathrm{BMI}$ alone [11-13]. In those with CKD, population-based studies suggest that measures of abdominal adiposity such as WC and WHR, rather than BMI, are better predictors of adverse outcomes such as mortality [14]. However, the association between the different measures of adiposity such as BMI and WC and complications arising from CKD has not been explored in previous studies. We hypothesized that obesity is associated with different CKD complications and that anthropometric measures such as BMI and WC have differential associations with CKD complications. As such, we studied the associations of WC and BMI with CKD complications such as anemia, secondary hyperparathyroidism, hyperphosphatemia, metabolic acidosis, hypoalbuminemia and hypertension among a nationally representative sample of US adults.

\section{Methods}

\section{Study Population}

We examined data from the National Health and Nutrition Examination Survey (NHANES), a nationally representative, complex and multistage probability of the US civilian, noninstitutionalized population conducted by the National Center for Health Statistics. The National Center for Health Statistics Ethics Review Board approved the study protocol and each participant provided written informed consent. Participants in the NHANES were interviewed in their homes and underwent a standardized physical examination in a mobile examination center. Self-reported information on demographics, socioeconomic status, health conditions, health behaviors and routine site of healthcare were obtained during the interview. The examination component consists of medical, dental and physiological measurements, as well as laboratory tests administered by highly trained medical personnel. The four 2-year cycles of the continuous NHANES, 1999-2000, 20012002, 2003-2004 and 2005-2006, were combined for this analysis. The study included 2,853 participants who met the following criteria: 20 years of age and older who (a) underwent medical exami- nation, (b) were not pregnant, (c) had BMI and WC measured, (d) had a BMI $\geq 18.5$, (e) had serum creatinine level and albumin-tocreatinine ratio results, (f) were not on dialysis and (g) had an estimated glomerular filtration rate $(\mathrm{eGFR}) \geq 15 \mathrm{ml} / \mathrm{min} / 1.73 \mathrm{~m}^{2}$.

\section{Measures}

Kidney Disease and Comorbidities

Participants with stage 1-4 CKD who were not on dialysis were included [stage 1-2 CKD: those with a urine albuminto-creatinine ratio (UACR) $\geq 30-299 \mathrm{mg} / \mathrm{g}$ (microalbuminuria) and $\geq 300 \mathrm{mg} / \mathrm{g}$ (macroalbuminuria) with eGFR $\geq 60 \mathrm{ml} / \mathrm{min} /$ $1.73 \mathrm{~m}^{2}$ or stage 3-4 CKD: eGFR $15-59 \mathrm{ml} / \mathrm{min} / 1.73 \mathrm{~m}^{2}$ ]. The eGFR was calculated according to the Chronic Kidney Disease Epidemiology Collaboration equations using calibrated creatinine $[15,16]$. Serum creatinine levels were corrected for the 1999-2000 and 2005-2006 surveys as suggested in the NHANES serum creatinine documentation [16]. The UACR was calculated from spot urine albumin and creatinine samples obtained. Diabetes was defined as self-reported if ever told by a doctor that the participant had 'diabetes or borderline diabetes'. Hypercholesterolemia was defined as the presence of total cholesterol > $200 \mathrm{mg} /$ $\mathrm{dl}$ and/or use of cholesterol-lowering medications. Liver disease was defined by the answer 'yes' to the question, 'Have you ever been told that you had any liver condition?'.

\section{Adiposity Measures}

Height and weight measurements were collected by trained health technicians using standardized techniques and equipment during the health examination conducted in each survey period. WC was measured midway between the lowest rib and the iliac crest with the participant standing. BMI was calculated as weight in kilograms divided by the measured height in meters squared and participants were classified as obese if they had a BMI $\geq 30$. WC was categorized as high risk for men with a measured WC $>102 \mathrm{~cm}$ and for women with a measured WC $>88 \mathrm{~cm}$. All others were considered low risk [17]. We also considered four different categories based on their BMI and WC data: (a) BMI $\geq 30$ and high WC, (b) BMI $\geq 30$ and low WC, (c) BMI $<30$ and high WC and (d) BMI $<30$ and low WC (fig. 1).

\section{CKD Complications}

Anemia was defined as hemoglobin $<13.5 \mathrm{~g} / \mathrm{dl}$ for males and $<12 \mathrm{~g} / \mathrm{dl}$ for females [18]. A serum bicarbonate level $<21 \mathrm{mEq} / \mathrm{l}$ was defined as the presence of metabolic acidosis and parathyroid hormone $(\mathrm{PTH})>70 \mathrm{pg} / \mathrm{ml}$ was defined as secondary hyperparathyroidism [19]. Hyperphosphatemia was defined as the presence of serum phosphorus $>4.5 \mathrm{mg} / \mathrm{dl}$ [19]. Hypoalbuminemia was defined as a serum albumin level $<4 \mathrm{~g} / \mathrm{dl}$. Hypertension was defined as the presence of systolic blood pressure $>140 \mathrm{~mm} \mathrm{Hg}$ and/or diastolic blood pressure $>90 \mathrm{~mm} \mathrm{Hg}$ or the use of antihypertensive medication.

\section{Statistical Analysis}

Demographics, comorbidities and CKD complications were compared between participants with $\mathrm{BMI} \geq 30$ and $<30$ and with high (WC $>102 \mathrm{~cm}$ in males and $>88 \mathrm{~cm}$ in females) and low WC using $t$ tests for continuous variables and Rao-Scott $\chi^{2}$ tests for categorical variables. Results were reported as mean \pm standard error for continuous variables and percent (95\% CI) for categorical variables. We examined the associations between different an- 
Fig. 1. Details of how CKD participants from different NHANES surveys were included in this study.

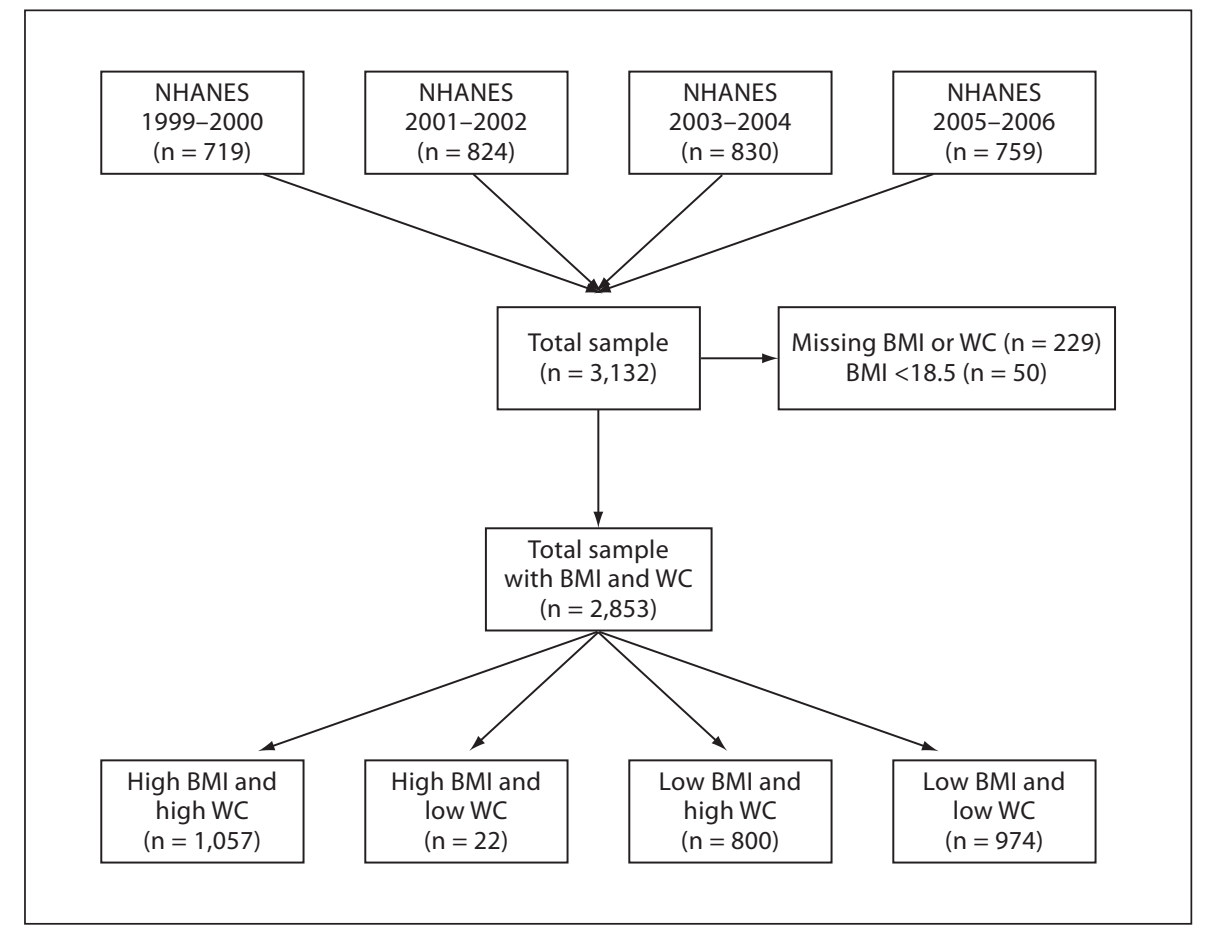

thropometric measures such as BMI (for every 2-point increase) and WC (for every $5-\mathrm{cm}$ increase) and CKD complications while adjusting for age, gender, African American race, diabetes, hypertension, liver disease (for hypoalbuminemia outcome only), smoking, UACR and eGFR.

Logistic regression analysis was also used to assess the associations between individual CKD complications and $\mathrm{BMI} \geq 30$ while adjusting for the above-mentioned variables. A sensitivity analysis that compared BMI $\geq 30$ to BMI 25-29.9 was also conducted. Similarly, logistic regression analysis was used to assess the associations between individual CKD complications and a high WC ( $>102 \mathrm{~cm}$ in males and $>88 \mathrm{~cm}$ in females) while adjusting for the relevant confounding variables mentioned above. BMI and WC were not included in these models due to collinearity (unweighted correlation $=0.87$ ).

In addition, logistic regression analysis categorized participants as: (a) BMI $\geq 30$ and high WC (obese based on both criteria) versus participants with $\mathrm{BMI}<30$ and low WC (nonobese based on both criteria) and (b) participants with $\mathrm{BMI}<30$ and high WC versus participants with $\mathrm{BMI}<30$ and low WC. This analysis was conducted while adjusting for the above-mentioned variables. We could not conduct a separate analysis for those with BMI $\geq 30$ and low WC versus participants with $\mathrm{BMI}<30$ and low WC due to the small sample size in the former $(\mathrm{n}=22)$.

All analyses were performed using survey procedures with SAS version 9.2 for Unix (SAS Institute, Cary, N.C., USA), which accounts for the sampling design of NHANES and appropriately weighted participants in statistical models. Graphs were produced using $\mathrm{R}$ version 2.12.2 (The R Foundation for Statistical Computing, Vienna, Austria).

Anthropometric Measures and CKD Complications

\section{Results}

\section{Participant Characteristics}

\section{$B M I \geq 30$ versus $B M I<30$.}

CKD participants with $\mathrm{BMI} \geq 30$ were younger [58.0 $(0.7)$ vs. $62.7(0.7)$ years] and had more non-Hispanic blacks (14.6 vs. 9.0\%) than CKD participants with BMI $<30$. A higher proportion of CKD participants with BMI $\geq 30$ had diabetes ( $p<0.001$; table 1 ). The mean $\mathrm{WC}$ of CKD participants with BMI $\geq 30$ was $115.6(0.6) \mathrm{cm}$ compared to $92.4(0.3) \mathrm{cm}$ among CKD participants with BMI $<30$ ( $\mathrm{p}<0.001)$. The mean eGFR was $75.1 \mathrm{ml} / \mathrm{min} /$ $1.73 \mathrm{~m}^{2}$ for those with BMI $\geq 30$ versus $71.2(1.0) \mathrm{ml} / \mathrm{min} /$ $1.73 \mathrm{~m}^{2}$ for the BMI $<30$ group $(\mathrm{p}=0.003$ ). The UACR was higher among those with $\mathrm{BMI} \geq 30$ than among those with $\mathrm{BMI}<30(\mathrm{p}=0.03)$. Table 1 lists additional participant characteristics based on their BMI.

\section{High versus Low WC}

CKD participants with high WC $(>102 \mathrm{~cm}$ in males and $>88 \mathrm{~cm}$ in females) were older [62.2 (0.6) vs. 58.6 (1.0) years] with a lesser proportion of males (37.9 vs. $52.8 \%$ ) than CKD participants with a low WC. A higher proportion of those with high WC had diabetes and 
Table 1. Characteristics of participants who were categorized as obese $(\mathrm{BMI} \geq 30)$ and nonobese $(\mathrm{BMI}<30)$ based on $\mathrm{BMI}$ criteria

\begin{tabular}{|c|c|c|c|}
\hline Male gender & $43.6(39.6,47.5)$ & $42.6(39.8,45.3)$ & 0.68 \\
\hline Race & & & $<0.01$ \\
\hline Non-Hispanic white & $68.5(63.9,73.1)$ & $74.7(71.0,78.5)$ & \\
\hline Other Hispanic & $6.2(3.3,9.1)$ & $4.6(2.2,7.0)$ & \\
\hline Other & $4.2(2.0,6.4)$ & $6.2(4.4,8.0)$ & \\
\hline \multicolumn{4}{|l|}{ Household income } \\
\hline$<20,000$ USD & $29.4(25.7,33.2)$ & $27.1(23.2,31.0)$ & 0.55 \\
\hline 20,000-44,999 USD & $34.4(29.9,38.9)$ & $34.0(30.8,37.1)$ & \\
\hline 45,000-74,999 USD & $19.5(15.3,23.7)$ & $22.7(18.9,26.5)$ & \\
\hline Hyperlipidemia & $68.9(65.0,72.7)$ & $68.4(65.6,71.3)$ & 0.83 \\
\hline Smoking & $16.1(13.5,18.8)$ & $19.6(17.1,22.0)$ & 0.052 \\
\hline BMI & $35.9 \pm 0.3$ & $25.2 \pm 0.1$ & $<0.001$ \\
\hline Waist circumference, $\mathrm{cm}$ & $115.6 \pm 0.6$ & $92.4 \pm 0.3$ & $<0.001$ \\
\hline $\mathrm{eGFR}, \mathrm{ml} / \mathrm{min} / 1.73 \mathrm{~m}^{2}$ & $75.1 \pm 1.1$ & $71.2 \pm 1.0$ & 0.003 \\
\hline CKD stage & & & $<0.001$ \\
\hline Stage $1-2$ & $58.8(54.7,63.0)$ & $49.3(46.0,52.6)$ & \\
\hline Stage $3 \mathrm{a}\left(\mathrm{eGFR} 45-59 \mathrm{ml} / \mathrm{min} / 1.73 \mathrm{~m}^{2}\right)$ & $29.1(25.2,32.9)$ & $36.9(34.1,39.7)$ & \\
\hline Stage $3 \mathrm{~b}\left(\mathrm{eGFR} 30-45 \mathrm{ml} / \mathrm{min} / 1.73 \mathrm{~m}^{2}\right.$ ) & $9.4(7.2,11.6)$ & $11.6(9.9,13.2)$ & \\
\hline Stage $4\left(\mathrm{eGFR} 15-29 \mathrm{ml} / \mathrm{min} / 1.73 \mathrm{~m}^{2}\right)$ & $2.7(1.7,3.7)$ & $2.3(1.5,3.1)$ & \\
\hline $\mathrm{UACR}, \mathrm{mg} / \mathrm{g}$ & $191.2 \pm 23.7$ & $137.7 \pm 11.3$ & 0.033 \\
\hline
\end{tabular}

Results are presented as percent $(95 \% \mathrm{CI})$ or as means \pm standard error. Stage $1-2 \mathrm{CKD}$ includes those with eGFR $>60 \mathrm{ml} / \mathrm{min} /$ $1.73 \mathrm{~m}^{2}$ and micro- or macroalbuminuria.

hyperlipidemia ( $\mathrm{p}<0.001$; table 2$)$. The mean BMI of CKD participants with high WC was 32.3 (0.2) compared to 23.9 (0.1) a mong those with low WC. The mean eGFR was $71.2 \mathrm{ml} / \mathrm{min} / 1.73 \mathrm{~m}^{2}$ for participants with high WC versus $75.7(1.3) \mathrm{ml} / \mathrm{min} / 1.73 \mathrm{~m}^{2}$ for those with low WC $(\mathrm{p}=0.004)$. The UACR was similar between those with high and low WC $(\mathrm{p}=0.21)$. Table 2 lists additional participant characteristics based on their WC.

\section{Associations between Anthropometric Measures and CKD Complications}

\section{Continuous Variables}

An increase in BMI by 2 points was associated with increased odds of having secondary hyperparathyroidism, hypoalbuminemia and hypertension (table 3). Similarly, an increase in WC by $5 \mathrm{~cm}$ was associated with increased odds of having secondary hyperparathyroidism, hypoalbuminemia and hypertension but also with lower odds of having anemia (table 3 ). 
Table 2. Characteristics of participants who were categorized as obese and nonobese based on WC criteria

\begin{tabular}{|c|c|c|c|}
\hline Age, years & $62.2 \pm 0.6$ & $58.6 \pm 1.0)$ & 0.002 \\
\hline Male gender & $37.9(35.0,40.8)$ & $52.8(48.5,57.1)$ & $<0.001$ \\
\hline Race & & & 0.33 \\
\hline Non-Hispanic white & $72.7(68.7,76.6)$ & $71.4(67.0,75.8)$ & \\
\hline Other Hispanic & $5.1(3.0,7.3)$ & $5.5(2.7,8.4)$ & \\
\hline Other & $4.7(3.0,6.5)$ & $6.7(4.1,9.3)$ & \\
\hline \multicolumn{4}{|l|}{ Household income } \\
\hline$<20,000$ USD & $29.9(26.1,33.6)$ & $24.4(20.6,28.2)$ & 0.011 \\
\hline 20,000-44,999 USD & $34.9(31.7,38.1)$ & $32.6(28.3,36.9)$ & \\
\hline 45,000-74,999 USD & $20.4(17.2,23.6)$ & $23.3(18.7,27.9)$ & \\
\hline Hyperlipidemia & $72.3(69.5,75.2)$ & $61.3(56.9,65.8)$ & $<0.001$ \\
\hline Smoking & $15.7(13.5,17.9)$ & $22.9(19.5,26.4)$ & $<0.001$ \\
\hline BMI & $32.3 \pm 0.2$ & $23.9 \pm 0.1$ & $<0.001$ \\
\hline Waist circumference, $\mathrm{cm}$ & $109.2 \pm 0.5$ & $87.0 \pm 0.4$ & $<0.001$ \\
\hline $\mathrm{eGFR}, \mathrm{ml} / \mathrm{min} / 1.73 \mathrm{~m}^{2}$ & $71.2 \pm 0.9$ & $75.7 \pm 1.3$ & 0.004 \\
\hline CKD stage & & & 0.05 \\
\hline Stage $1-2$ & $51.5(48.1,54.8)$ & $56.2(51.9,60.5)$ & \\
\hline Stage $3 \mathrm{a}\left(\mathrm{eGFR} 45-59 \mathrm{ml} / \mathrm{min} / 1.73 \mathrm{~m}^{2}\right)$ & $34.1(31.3,36.9)$ & $33.2(29.4,36.9)$ & \\
\hline Stage $3 \mathrm{~b}\left(\mathrm{eGFR} 30-45 \mathrm{ml} / \mathrm{min} / 1.73 \mathrm{~m}^{2}\right.$ ) & $11.6(9.7,13.6)$ & $8.9(6.9,10.9)$ & \\
\hline Stage $4\left(\right.$ eGFR $\left.15-29 \mathrm{ml} / \mathrm{min} / 1.73 \mathrm{~m}^{2}\right)$ & $2.8(2.1,3.6)$ & $1.7(0.9,2.6)$ & \\
\hline $\mathrm{UACR}, \mathrm{mg} / \mathrm{g}$ & $168.3 \pm 16.6$ & $140.8 \pm 15.5$ & 0.21 \\
\hline
\end{tabular}

Results are presented as percent $(95 \% \mathrm{CI})$ or as means \pm standard error. Stage $1-2 \mathrm{CKD}$ includes those with eGFR $>60 \mathrm{ml} / \mathrm{min} /$ $1.73 \mathrm{~m}^{2}$ and micro- or macroalbuminuria. High $\mathrm{WC}=\mathrm{WC}>102 \mathrm{~cm}$ in $\mathrm{men}$ and $>88 \mathrm{~cm}$ in women.

\section{Categorical Analyses}

$\mathrm{BMI} \geq 30$ versus $\mathrm{BMI}<30$

CKD participants with $\mathrm{BMI} \geq 30$ have higher odds of hypoalbuminemia and hypertension than CKD participants with BMI $<30$ when adjusted for relevant confounding variables (table 4). There was a nonsignificant increase in the odds for secondary hyperparathyroidism among those with BMI $\geq 30$ (table 4 ). There were no associations between $\mathrm{BMI} \geq 30$ and hyperphosphatemia, metabolic acidosis and anemia. Similar associations were noted when BMI $\geq 30$ was compared to BMI 25-29.9.
High versus Low WC

CKD participants with high WC have higher odds of hypoalbuminemia and hypertension and lower odds of having anemia than CKD participants with low WC when adjusted for relevant confounding variables (table 4). There were no associations between high WC and hyperphosphatemia, secondary hyperparathyroidism and metabolic acidosis. 
Table 3. Associations between CKD complications and BMI and $\mathrm{WC}$ when examined as a continuous measure

\begin{tabular}{|c|c|c|}
\hline CKD complications & Odds ratio $(95 \% \mathrm{CI})$ & $\mathrm{p}$ value \\
\hline \multicolumn{3}{|l|}{ Anemia } \\
\hline BMI per 2-point increase & $0.95(0.90,1.01)$ & 0.06 \\
\hline WC per 5-cm increase & $0.95(0.90,0.99)$ & 0.04 \\
\hline \multicolumn{3}{|l|}{ Hypoalbuminemia $^{\mathrm{a}}$} \\
\hline BMI per 2-point increase & $1.13(1.09,1.18)$ & $<0.001$ \\
\hline WC per 5-cm increase & $1.14(1.10,1.19)$ & $<0.001$ \\
\hline \multicolumn{3}{|l|}{ Metabolic acidosis } \\
\hline BMI per 2-point increase & $1.02(0.95,1.10)$ & 0.57 \\
\hline WC per 5-cm increase & $1.00(0.94,1.06)$ & 0.94 \\
\hline \multicolumn{3}{|l|}{ Secondary hyperparathyroidism } \\
\hline BMI per 2-point increase & $1.08(1.02,1.14)$ & 0.01 \\
\hline WC per 5-cm increase & $1.08(1.02,1.15)$ & 0.01 \\
\hline \multicolumn{3}{|l|}{ Hyperphosphatemia } \\
\hline BMI per 2-point increase & $0.99(0.93,1.06)$ & 0.86 \\
\hline WC per 5-cm increase & $1.00(0.94,1.04)$ & 0.93 \\
\hline \multicolumn{3}{|l|}{ Hypertension $^{\mathrm{b}}$} \\
\hline BMI per 2-point increase & $1.17(1.12,1.22)$ & $<0.001$ \\
\hline WC per 5-cm increase & $1.17(1.12,1.22)$ & $<0.001$ \\
\hline \multicolumn{3}{|c|}{$\begin{array}{l}\text { CKD complications adjusted for age, African American race, gender, } \\
\text { smoking, diabetes, hypertension, log UACR and eGFR. } \\
\text { a Adjusted for age, African American race, gender, smoking, diabetes, } \\
\text { eGFR, log log UACR, liver disease and hypertension. } \\
\text { b Adjusted for age, African American race, gender, smoking, diabetes, } \\
\text { log UACR and eGFR. }\end{array}$} \\
\hline
\end{tabular}

$\mathrm{BMI} \geq 30$ and High WC versus $\mathrm{BMI}<30$ and Low WC CKD participants with $\mathrm{BMI} \geq 30$ and high WC (who would meet both the criteria of obesity) have higher odds of secondary hyperparathyroidism, hypoalbuminemia and hypertension than participants with $\mathrm{BMI}<30$ and low WC when adjusted for relevant confounding variables (fig. 2).

$\mathrm{BMI}<30$ and High WC versus $\mathrm{BMI}<30$ and Low WC CKD participants with $\mathrm{BMI}<30$ and high WC were not associated with any increased likelihood of CKD complications when compared to participants with BMI $<30$ and low WC when adjusted for relevant confounding variables (fig. 2).

\section{Discussion}

Our analysis of representative US adults with kidney disease shows that the anthropometric obesity measures such as BMI and WC are associated with different CKD complications. These associations are similar when examined as continuous variables. However, when examined as a categorical variable from standard definitions
Table 4. Odds of having CKD complications among obese participants based on different BMI and WC categories

\begin{tabular}{|c|c|c|}
\hline CKD complications & Odds ratio $(95 \% \mathrm{CI})$ & $\mathrm{p}$ value \\
\hline \multicolumn{3}{|l|}{ Anemia } \\
\hline BMI $>30$ vs. $<30$ & $0.77(0.56,1.07)$ & 0.12 \\
\hline High vs. low WC & $0.73(0.55,0.97)$ & 0.03 \\
\hline \multicolumn{3}{|l|}{ Hypoalbuminemia $^{\mathrm{a}}$} \\
\hline BMI >30 vs. $<30$ & $1.78(1.34,2.36)$ & $<0.001$ \\
\hline High vs. low WC & $1.54(1.20,1.98)$ & $<0.001$ \\
\hline \multicolumn{3}{|l|}{ Metabolic acidosis } \\
\hline BMI $>30$ vs. $<30$ & $1.17(0.73,1.88)$ & 0.51 \\
\hline High vs. low WC & $0.92(0.53,1.60)$ & 0.76 \\
\hline \multicolumn{3}{|c|}{ Secondary hyperparathyroidism } \\
\hline BMI >30 vs. $<30$ & $1.38(0.96,1.98)$ & 0.08 \\
\hline High vs. low WC & $1.24(0.82,1.86)$ & 0.31 \\
\hline \multicolumn{3}{|l|}{ Hyperphosphatemia } \\
\hline BMI >30 vs. $<30$ & $0.88(0.57,1.35)$ & 0.56 \\
\hline High vs. low WC & $1.11(0.74,1.67)$ & 0.61 \\
\hline \multicolumn{3}{|l|}{ Hypertension $^{\mathrm{b}}$} \\
\hline BMI $>30$ vs. $<30$ & $2.41(1.89,3.07)$ & $<0.001$ \\
\hline High vs. low WC & $2.19(1.65,2.90)$ & $<0.001$ \\
\hline \multicolumn{3}{|c|}{$\begin{array}{l}\text { CKD complications adjusted for age, African American race, gender } \\
\text { smoking, diabetes, hypertension, log UACR and eGFR. } \\
\text { a Adjusted for age, African American race, gender, smoking, diabetes } \\
\text { eGFR, log UACR, liver disease and hypertension. } \\
\text { b Adjusted for age, African American race, gender, smoking, diabetes } \\
\text { log UACR and eGFR. }\end{array}$} \\
\hline
\end{tabular}

of obesity based on BMI and WC measures, there were differential associations. Participants with BMI $\geq 30$ and high WC (obese based on both criteria) had higher odds of secondary hyperparathyroidism, hypoalbuminemia and hypertension than participants who had low WC and $\mathrm{BMI}<30$ (nonobese based on both criteria). In addition, among those with $\mathrm{BMI}<30$, the presence of high WC was not associated with any CKD complications.

Previous studies have explored the associations between various adiposity measures and incident CKD. Secondary analysis of the Cardiovascular Health Study and Atherosclerosis Risk in Communities Study showed that WHR but not BMI was associated with incident CKD and mortality [20]. In a nondiabetic cohort, WC and BMI but not WHR were associated with lower eGFR [21]. Studies exploring the associations of different anthropometric measures with kidney disease progression and mortality are limited. Secondary analysis of the Atherosclerosis Risk in Communities Study showed that the associations of obesity with mortality differed by the presence or absence of CKD, suggesting that kidney disease does not reverse the metabolic effects of obesity [22]. Recently, Kramer et al. [14] reported higher mortality rates for WC $>94 \mathrm{~cm}$ in men and $>80 \mathrm{~cm}$ in women, while no such as- 
Fig. 2. Odds of having CKD complications for participants with different BMI and WC categories.

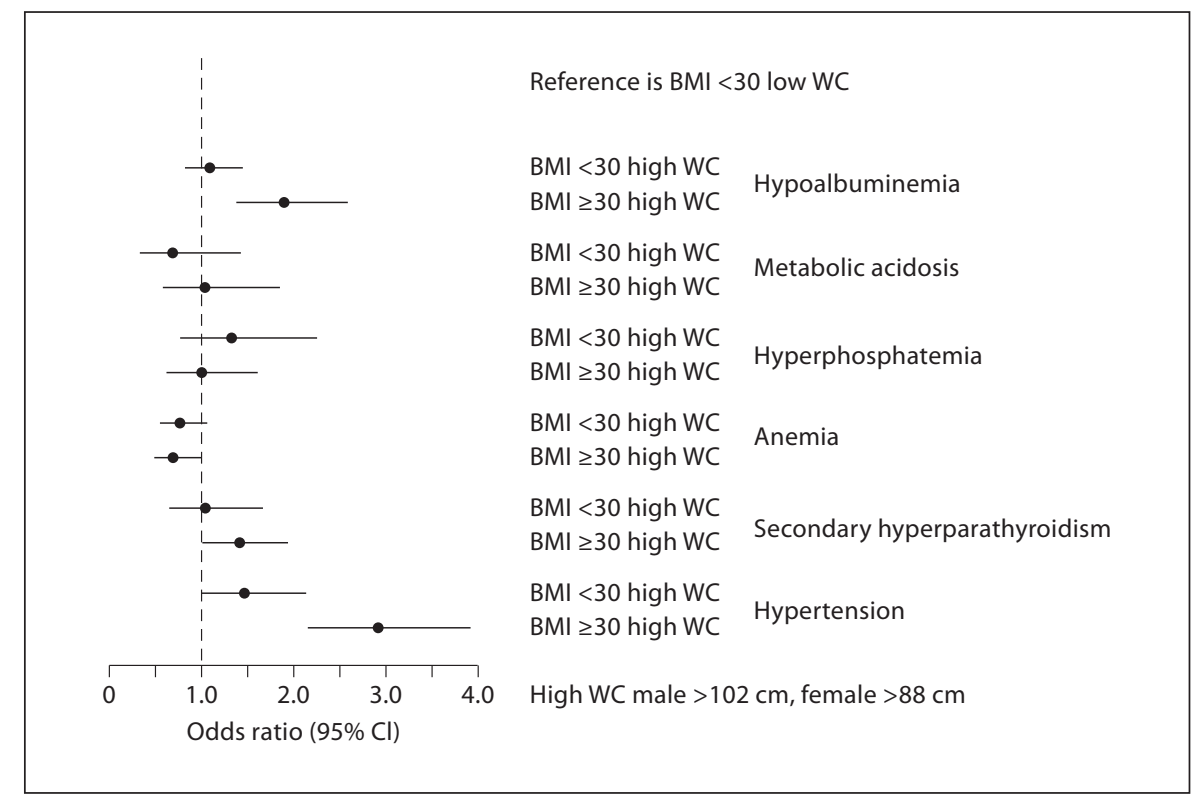

sociations were noted for higher BMI categories among 5,805 CKD participants. Our study adds to this growing body of evidence regarding the utility of these different adiposity measures in the CKD population. In addition, these findings highlight the different results that might be obtained when examining these anthropometric variables as continuous and categorical variables.

Associations between BMI $\geq 30$ and secondary hyperparathyroidism have been reported previously, but the associations of BMI and WC with other CKD complications have not been explored. Kovesdy et al. [23] reported that higher BMI levels were associated with higher PTH levels among patients who were not dependent on dialysis. Similarly, secondary analysis of the Kidney Early Evaluation Program data showed that higher BMI was associated with high PTH levels independent of confounding variables [24]. WC data was not available in these studies. In addition to the findings from previous studies, we found higher odds of having PTH $>70 \mathrm{pg} / \mathrm{ml}$ with both increasing BMI and WC. Some proposed explanations that may explain these associations include lower 25(OH)D levels and lower physical activity (thus lower sun exposure) noted among those with higher BMI and WC. In addition, the decreased bioavailability of vitamin $\mathrm{D}$ due to its deposition in adipocytes among those who are obese might also contribute to the higher rates of secondary hyperparathyroidism [25].

When examined as both continuous and categorical variables, participants with a high BMI and WC had high- er odds of having hypoalbuminemia among CKD participants. Obesity is a state of inflammation and thus hypoalbuminemia might reflect the higher inflammatory burden among those who are obese rather than nutritional status alone $[26,27]$. We also examined whether the presence of $\mathrm{BMI} \geq 30$ and high WC were associated with higher Hs-CRP levels. Hs-CRP levels were higher among those with $\mathrm{BMI} \geq 30$ and high WC and this data supports the inflammation hypothesis (tables 1 and 2). We planned to conduct a sensitivity analysis by defining hypoalbuminemia as serum albumin $<3.5 \mathrm{~g} / \mathrm{dl}$ but the relatively small number of participants precluded this analysis.

As expected, the presence of higher BMI and WC were associated with increased odds of having hypertension among CKD participants, and this data is similar to that seen in the general population. However, there was a negative association between high WC and anemia noted in this analysis. To our knowledge, no studies have reported associations between anemia and obesity in both CKD and non-CKD populations except that a populationbased study reported no significant associations between anemia and obesity in the absence of CKD [28]. The exact mechanisms that might explain these associations are unclear at present and these associations should be reexamined and confirmed in future studies.

BMI data is readily available in clinical settings and whether WC details provide additional prognostic information relating to CKD complications in this population is unclear. Hence, we examined the associations between 
$\mathrm{BMI}<30$ and high WC and CKD complications. Our results suggest that BMI data alone might be sufficient to predict CKD complications in those with lower BMI. We could not conduct an analysis among participants with $\mathrm{BMI} \geq 30$ and low $\mathrm{WC}$ versus $\mathrm{BMI}<30$ and low WC to examine the utility of BMI alone due to the small sample size.

One strength of this study was the inclusion of a nationally representative sample with adequate representation of various ethnic groups in the United States. This analysis is subject to limitations that include the crosssectional study design of NHANES surveys that precludes the opportunity for studying temporal associations. Also, the use of a single UACR measurement in the NHANES surveys might lead to misclassification of CKD, especially among participants with early-stage CKD. Further, the number of participants with advanced CKD is minimal and whether these associations exist among those with advanced kidney disease needs to be examined in future studies. We also did not have body composition measures such as DEXA or computed tomography measures which would provide more detailed insight into the role of the body composition.
In summary, anthropometric measures such as BMI and WC are associated with secondary hyperparathyroidism, hypoalbuminemia and hypertension among those with CKD. Higher WC among those with BMI $<30$ is not associated with CKD complications. These associations suggest the need for closely monitoring the development of complications relating to $\mathrm{CKD}$ among those who are obese.

\section{Disclosure Statement}

S.D.N. is supported by a career development award from the National Center for Research Resources and the National Center for Advancing Translational Sciences, National Institutes of Health (grant No. RR024990). J.P.K. is supported by the National Institutes of Health (RO1 DK089547). J.D.S. is supported by NIH/NIDDK (R01 DK085185) and investigator-initiated grant support from PhRMA foundation, Genzyme and Roche Organ Transplant Research Foundation. M.J.S. is supported by K24 DK078204. The content of this paper is solely the responsibility of the authors and does not necessarily represent the official views of the NIH. The authors have no relevant financial interest in the study.

\section{References}

- 1 Finucane MM, Stevens GA, Cowan MJ, Danaei G, Lin JK, Paciorek CJ, Singh GM, Gutierrez HR, Lu Y, Bahalim AN, Farzadfar F, Riley LM, Ezzati M, Global Burden of Metabolic Risk Factors of Chronic Diseases Collaborating Group (Body Mass Index): National, regional, and global trends in body mass index since 1980: systematic analysis of health examination surveys and epidemiological studies with 960 country-years and 9.1 million participants. Lancet 2011;377: 557-567.

-2 Coresh J, Selvin E, Stevens LA, Manzi J, Kusek JW, Eggers P, Van Lente F, Levey AS: Prevalence of chronic kidney disease in the United States. JAMA 2007;298:2038-2047.

3 Navaneethan SD, Kirwan JP, Arrigain S, Schreiber MJ, Sehgal AR, Schold JD: Overweight, obesity and intentional weight loss in chronic kidney disease: NHANES 19992006. Int J Obes (Lond) 2012, DOI: 10.1038/ ijo.2012.7.

$\checkmark 4$ Hsu CY, McCulloch CE, Iribarren C, Darbinian J, Go AS: Body mass index and risk for end-stage renal disease. Ann Intern Med 2006;144:21-28. $\checkmark 5$ Griffin KA, Kramer H, Bidani AK: Adverse renal consequences of obesity. Am J Physiol Renal Physiol 2008;294:F685-F96.

6 Kovesdy CP, Czira ME, Rudas A, Ujszaszi A, Rosivall L, Novak M, Kalantar-Zadeh K, Molnar MZ, Mucsi I: Body mass index, waist circumference and mortality in kidney transplant recipients. Am J Transplant 2010; 10:2644-2651.

$>7$ Kalantar-Zadeh K, Abbott KC, Salahudeen AK, Kilpatrick RD, Horwich TB: Survival advantages of obesity in dialysis patients. Am J Clin Nutr 2005;81:543-554.

-8 Artero EG, Lee DC, Ruiz JR, Sui X, Ortega FB, Church TS, Lavie CJ, Castillo MJ, Blair SN: A prospective study of muscular strength and all-cause mortality in men with hypertension. J Am Coll Cardiol 2011;57:1831-1837.

$\checkmark 9$ Wijnhoven HA, Snijder MB, van Bokhorst-de van der Schueren MA, Deeg DJ, Visser M: Region-specific fat mass and muscle mass and mortality in community-dwelling older men and women. Gerontology 2012;58:32-40.

10 Lapice E, Maione S, Patti L, Cipriano P, Rivellese AA, Riccardi G, Vaccaro O: Abdominal adiposity is associated with elevated Creactive protein independent of $\mathrm{BMI}$ in healthy nonobese people. Diabetes Care 2009;32:1734-1736.
11 Bombelli M, Facchetti R, Sega R, Carugo S, Fodri D, Brambilla G, Giannattasio C, Grassi G, Mancia G: Impact of body mass index and waist circumference on the long-term risk of diabetes mellitus, hypertension, and cardiac organ damage. Hypertension 2011; 58:1029-1035.

12 Taylor AE, Ebrahim S, Ben-Shlomo Y, Martin RM, Whincup PH, Yarnell JW, Wannamethee SG, Lawlor DA: Comparison of the associations of body mass index and measures of central adiposity and fat mass with coronary heart disease, diabetes, and allcause mortality: a study using data from 4 UK cohorts. Am J Clin Nutr 2010;91:547556.

13 Coutinho T, Goel K, Corrêa de Sá D, Kragelund C, Kanaya AM, Zeller M, Park JS, Kober L, Torp-Pedersen C, Cottin Y, Lorgis L, Lee SH, Kim YJ, Thomas R, Roger VL, Somers VK, Lopez-Jimenez F: Central obesity and survival in subjects with coronary artery disease: a systematic review of the literature and collaborative analysis with individual subject data. J Am Coll Cardiol 2011;57:18771886.
Navaneethan/Kirwan/Arrigain/ Schreiber/Sarnak/Schold 
14 Kramer H, Shoham D, McClure LA, DurazoArvizu R, Howard G, Judd S, Muntner P, Safford M, Warnock DG, McClellan W: Association of waist circumference and body mass index with all-cause mortality in CKD: The REGARDS (Reasons for Geographic and Racial Differences in Stroke) Study. Am J Kidney Dis 2011;58:177-185.

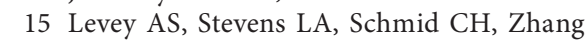
YL, Castro AF 3rd, Feldman HI, Kusek JW, Eggers P, Van Lente F, Greene T, Coresh J, CKD-EPI (Chronic Kidney Disease Epidemiology Collaboration): A new equation to estimate glomerular filtration rate. Ann Intern Med 2009;150:604-612.

- 16 Selvin E, Manzi J, Stevens LA, Van Lente F, Lacher DA, Levey AS, Coresh J: Calibration of serum creatinine in the National Health and Nutrition Examination Surveys (NHANES) 1988-1994, 1999-2004. Am J Kidney Dis 2007;50:918-926.

17 World Health Organization. 2011. http:// whqlibdoc.who.int/publications/2011/ 9789241501491_eng.pd (last accessed June 23, 2012).

18 National Kidney Foundation Anemia Guidelines. 2006. http://www.kidney.org/professionals/KDOQI/guidelines_anemia/index. htm (last accessed June 23, 2012).
19 National Kidney Foundation. 2003. http:// www.kidney.org/professionals/KDOQI/ guidelines_bone/index.htm (last accessed June 23, 2012).

20 Elsayed EF, Sarnak MJ, Tighiouart H, Griffith JL, Kurth T, Salem DN, Levey AS, Weiner DE: Waist-to-hip ratio, body mass index, and subsequent kidney disease and death. Am J Kidney Dis 2008;52:29-38.

21 Burton JO, Gray LJ, Webb DR, Davies MJ, Khunti K, Crasto W, Carr SJ, Brunskill NJ: Association of anthropometric obesity measures with chronic kidney disease risk in a non-diabetic patient population. Nephrol Dial Transplant 2012;27:1860-1866.

22 Kwan BC, Murtaugh MA, Beddhu S: Associations of body size with metabolic syndrome and mortality in moderate chronic kidney disease. Clin J Am Soc Nephrol 2007; 2:992-998.

23 Kovesdy CP, Ahmadzadeh S, Anderson JE, Kalantar-Zadeh K: Obesity is associated with secondary hyperparathyroidism in men with moderate and severe chronic kidney disease. Clin J Am Soc Nephrol 2007;2: 1024-1029.
24 Saab G, Whaley-Connell A, McFarlane SI, Li S, Chen SC, Sowers JR, McCullough PA, Bakris GL, Kidney Early Evaluation Program Investigators: Obesity is associated with increased parathyroid hormone levels independent of glomerular filtration rate in chronic kidney disease. Metabolism 2010;59: 385-389.

25 Wortsman J, Matsuoka LY, Chen TC, Lu Z, Holick MF: Decreased bioavailability of vitamin D in obesity. Am J Clin Nutr 2000;72: 690-693.

26 Ramkumar N, Cheung AK, Pappas LM, Roberts WL, Beddhu S: Association of obesity with inflammation in chronic kidney disease: a cross-sectional study. J Ren Nutr 2004;14:201-207.

27 Eustace JA, Astor B, Muntner PM, Ikizler TA, Coresh J: Prevalence of acidosis and inflammation and their association with low serum albumin in chronic kidney disease. Kidney Int 2004;65:1031-1040.

28 Ausk KJ, Ioannou GN: Is obesity associated with anemia of chronic disease? A population-based study. Obesity (Silver Spring) 2008; 16:2356-2361. 